\section{A REPORT ON}

\section{THE COMPLETE ABANDONMENT OF THE OPERATION FOR REMOVING ENTIRE CALCULI FROM THE BLADDER ;}

AND THE METHODS EMPLOYED INSTEAD AT THE CIVIL HOSPITAL, HYDERABAD, SINDH.

By Surgeon-Major J. FORBES KEITH, M.D., C.M.Aber., Civil Surgeon and Superintendent Medical School.

I THINK it is my duty to lay before the profession a report on the complete abandonment of the operation for removing calculi entire from the bladder, and the methods employed instead, in the Civil Hospital under my charge.

As a preliminary observation, I may remark that my experiences in this branch of surgery are, as far as I am aware, unique. In the course of the three years I have held this appointment I have operated 739 times for stone. In the month of May, 1891, I performed 50 operations for stone-37 lithotrities and 13 by the other methods, to be subsequently described-all successful; notwithstanding that the thermometer stood at $104^{\circ}$ in the operating theatre, and that the cases operated upon were indiscriminately undertaken as to age, sex, duration of disease, condition of health, or size of stone.

\section{I.-LITHOTRITY.}

As performed in this hospital, there need be no longer any hesitation in calling the operation by this name, aspiration, as an integral part of the operation, being almost, if not entirely, abandoned. Lithotrity is always performed here when the screw of the largest lithotrite the urethra can readily admit coincides with the diameter of the stone, in other words, when the diameter of the stone is small enough to allow the two screws (male and female) of the largest lithotrite the urethra can readily admit to combine with a hold sufficiently powerful to smash the stone. One exception to this rule, as far as my experience goes, is when the stone is too hard to be thus dealt with, in which case the hammer and chisel method to be hereafter described is adopted. In my first attempt to crush such stones I have had two accidents in about 100 cases. Once I broke the female screw of a fine new lithotrite just out from home, and once dislodged the male blade from the female at the angle of the jaw and bent it backwards towards the screw.

After the administration of chloroform, the first step is to thoroughly wash out the rectum with Condy. Lithotrity cannot be elegantly performed if the finger in the rectum intimately co-operating with the lithotrite or catheter in the bladder is constantly coming in contact with fæces. The bladder itself must also be thoroughly washed out if the urine is in any way tainted, as it frequently is in the aged, after which it will be found more tolerant of the auxiliary fluid. When a sufficient quantity of the latter has been introduced, the point of the lithotrite on its first introduction is met by the index finger of the left hand immediately on a plane behind the sphincter ani, and is then guided by the finger through the prostate and into the bladder. The information gained is to me of paramount importance, as my finger in the rectum never loses sight (so to speak) of the relation between the stone and lithotrite in the bladder. Further, the quantity of auxiliary fluid, which is readily detected by its bulging behind the prostate, the position of the stone with its relation to the lithotrite, the amount, character, and position of the debris, with its relation to the evacuating catheter, and any debris lurking amongst irregularities of the mucous membrane of the bladder or behind an enlarged prostate-all these conditions are readily distinguishable by the finger in the rectum co-operating with the lithotrite or catheter, as the case may be, in the bladder.

I mentioned that lithotrity was performed when the diameter of the stone coincided with the screw of the largest lithotrite the urethra was capable of readily admitting; but although the stone is broken up in the first instance by the largest instrument admissible, a size smaller is preferred to finish the operation. Experience taught me this lesson.
Some stones break up into finely divided mud or sandi. which, mixing with the fluid in the bladder, wells ap between the lithotrite and the walls of the urethra. It has various colours according to the quality of the stone, appearing sometimes almost milky white, and passing through various shades such as from meerschaum and fawn to brick-red. The welling up of these colours always warns me not to go on working with the largest lithotrite the urethra can admit, but. to change it for one of much smaller size, otherwise you will find great difficulty in removing it owing to the instrument having lost its glossy smoothness and become coated by a bluish-black film, and the urethral mucous membrane itsel 9 will be found to have lost its oily smoothness, and become coated by finely divided mud. I may mention in passing that chemical action, moreover, is not absent, for I have noticed effervescence during the operation when crushing: meerschaum-coloured stones, and their debris have a peculiar way of adhering to the walls of the bladder, requiring force to separate it, and gas bubbles remain intimately mixed up with the debris until it becomes dried.

Along with these there is another danger mentioned by Surgeon-Major Keegan, namely, spasmodic irritation caused by the 'frequent passage of instruments along the mucous membrane of the urethra, and there is also the continual friction of the male blade of the lithotrite, but the result of all these circumstances can be avoided, and all anxiety removed by operating with a smaller-sized lithotrite than the urethra is capable of readily admitting. This is my invariable practice, and I have rarely any cause now for anxiety except with very young children with very narrow urethræ which admit with difficulty, and sometimes not at all, the smallest lithotrites that can be made.

I have mentioned that as the aspirator is very rarely used for the purpose of evacuating the debris of calculi from the bladder, the term lithotrity, as the operation is performed here, is peculiarly applicable. No surgeon familiar with the numerous manipulations connected with the various stages of this operation can have failed to observe that the expulsive power of the bladder is normally greater than might at first be anticipated. As illustrations. it may not be considered superfluous to bring forward the following facts, which are intended to have a twofold significance : not only to demonstrate the expulsive power of the bladder, but also to show what reasons led me to abandon the aspirator as a chief factor in the operation.

1. Some time ago a boy, about 8 years of age, was admitted into hospital suffering from retention; he was brought into the operating theatre, and his case, with the diagnosis, was handed to me. He was placed on the table, and it was observed that urine had accumulated to some extent in the bladder. A catheter was introduced, but it proceeded only a little way, when it was found that there was a small calculus impacted midway between the scrotum and glans penis. Under chloroform I tried to move it, but it would not stir out of its place. When I was making preparations to slit open the urethra, the patient made a violent strain, urine was voided, and the calculus shot clean out of the urethra over the table and fell into the basin below. No one would have thought of introducing an instrument into this child's urethra with a diameter equal to that of this little oblong pebble so summarily expelled from it. Calculi carried high up the urethra and impacted in like manner are, as every surgeon is aware, of frequent occurrence.

2. While pouring the auxiliary fluid into the bladder preparatory to the operation, and holding the nozzle of the syringe in the meatus urinarius externus, I have observed, when the patient was not profoundly under the influence of chloroform, the piston, which had been pressed quite home and all fluid expelled from the syringe, gently but surely forced back again, and I have also observed it rising sometimes to the middle of the syringe, and sometimes actually reaching its mouth.

3. Again, I have noticed that after the introduction of the lithotrite, when the auxiliary fluid could not make its way up between the walls of the urethra and lithotrite, it forced its way up between the stems (male and female) of the lithotrite, and appeared like little beads on its shaft above the glians penis; and during the operation these beads will be seen coloured by the débris. 
4. Lastly, on the first introduction of the evacuating catheter I have often had it blocked so effectually that the aspirator was powerless in removing the obstacle; that the introduction of the stylette and the application of force were also ineffectual, and at last the catheter had to be withdrawn and another one used in its place, as valuable time would be occupied in extracting the débris from it; and I have seen a column of debris expelled from its mouth and shot in a parabola 6 feet beyond the operating table. This vis a tergo appeared so great that the addition of vis a fronte, namely, aspiration, seemed to me superfuous.

On the other hand I had certain objections to the aspirator. (1) I have observed that after the first movement of aspiration a certain amount of mud is always mixed up with the fluid in the aspirator, and it increases indefinitely as aspiration proceeds, and for a longer or shorter period muddy water is thrown backwards and forwards between the aspirator and the bladder. I have noticed the fluid so impregnated with mud that I could not see the heavier particles falling through it, and could only know I was gaining ground by the general accumulation of débris at the bottom of the bulb. Again (2) in old subjects who are invariably sufferers more or less from genito-urinary irritation, whose prostate glands and adjacent structures are congested, softened, and sometimes organically changed-whom you can scarcely touch without exciting hæmorrhage-in them you find that, with the first aspiratory movement, not only mud but (however delicate your manipulations may be) blood is also mixed with the fluid in the aspirator. (3) If care be not taken to keep the evacuating catheter always full of fluid at the moment it is connected with the aspirator air will, along with the mud and blood, get churned backwards and forwards between aspirator and bladder. (4) During aspiration I have seen patients wince, even when under chloroform, when débris was forced against the walls of the bladder; for, if it rattles against the catheter, as it may be distinctly heard to do, it must also beat with an equal amount of force against the vesical walls. This may injure the mucous membrane of the bladder and evil results follow.

The two orders of facts connected with the bladder and aspirator were being continually contrasted together in my mind, and I confess to entertaining a certain amount of prejudice against the faults inherent in the construction of the aspirator. But although these defects kept me constantly thinking upon the possibility of remedying them, it never for once entered my mind to abandon the aspirator until I had actually done so for some time. Unwilling to pass blood through the aspirator if I could avoid it, and searching to counteract the defects of the instrument, I unconsciously found myself using the aspirator as a syringe. It was applied to the evacuating catheter, its contents gently emptied into the bladder, and the stopcock shut; after which the aspirator was removed, in order to be refilled, and used again in the same way. Then the water, with large fragments of debris, tinged more or less with blood, would escape, always with force, sometimes with considerable violence, from the mouth of the evacuating catheter. By a few repetitions of this process, I found that I not only got rid of the anxiety of having the aspirator contaminated with blood, but also of the to-andfro movement between the bladder and the aspirator of debris, blood, and air, and that the evacuation of the debris from the bladder was as effectually performed as if I had been working with the aspirator itself.

Having groped my way so far in counteracting the defects of the aspirator, the next step was easy and quite natural namely, to use a syringe instead of the aspirator, which had for some time now been performing this degraded office with its own proper function held in abeyance. I continued to use the syringe for some time, and then an apparatus was contrived which was very simple but at the same time very effective, and which successfully competed with the aspirator and superseded the syringe in the process of evacuation of the debris of calculi from the bladder, and adapted itself with peculiar facility to the co-operative process mentioned above between the finger in the rectum and the catheter in the bladder.

At the other end from the eye of the evacuating catheter and on its opposite side another opening is made close up at its mouth, similar to the eje or like the hole of a flute, which can be closed by the finger or thumb, as may be found convenient. This evacuating catheter is then attached to one end of a long piece of india-rubber tubing, which by its other end is connected with a little pipe or tube which issues from the bottom of an old kerosene oil tin case partially filled with boracic acid lotion of the proper strength. This simple apparatus forms a complete substitute for the aspirator in urethral lithotrity. When the stone is crushed and ready for evacuation the catheter is oiled and introduced into the bladder, an assistant in the meantime pinching the indiarubber tubing between his finger and thumb to keep the water from flowing out of the catheter while it is being introduced. When the catheter is in the bladder the operator closes the flute-like opening with his thumb or forefinger, and the assistant simultaneously sets the india-rubber tubing free. Fluid flows into the bladder for a short period, and then stops of itself, as can be easily seen by a glass indicator which is attached to the apparatus. Directly the fluid stops the operator with a simultaneous movement opens the flutelike eye in the catheter and pinches the india-rubber tubing. Fluid and debris issue with violence sometimes, always with sufficient force, from the flute-like opening.

On repetition of this process for a few times the debris of most stones is rapidly evacuated. In children, where the debris must be reduced to finely divided powder or mud before it can get through the eyes or cannulæ of such small catheters, evacuation of the debris can be effected by merely letting the water fall out of the syringe into the mouth of the evacuating catheter without in any way connecting them, and the reflex action of the bladder thus excited will at once cause the evacuation of the debris. With the irrigation stopcock made by Joseph Leiter, of Vienna (which can be opened and shut by a backward and forward movement of the thumb) attached to the india-rubber tubing instead of the evacuating catheter itself, a permanently going syringe can be held in the hand, and its nozzle can be connected with, or withdrawn from, the evacuating catheter at pleasure.

Since receiving my new instruments from home (in February, 1891) I have had a series of 100 operations without a death, and 157 with 3 deaths.

\section{II.-Perineal Lithotrity.}

When the diameter of the stone is too large for the screw of the largest lithotrite the urethra can readily admit, then recourse is had to the second or perineal method, or perineal lithotrity. It is only a modification of the first method, which may be distinguished as " urethral " in contradistinction to "perineal."

When I took over charge of this appointment there was in the hospital a little girl, about 9 years of age, who had been lately operated upon for stone by the cutting method. When she was lying quietly on her back the urine collected in small quantities in the bladder, but when she assumed the perpendicular posture all the accumulated urine escaped with a rush.

This case made such a profound impression on my mind that I determined to try some other operation. There were a few lithotrity instruments in hospital, but some of them were old and of a very inferior sort, and none of them were fenestrated. However, by the kindness of the engineer in charge of the municipal workshops here I got them as well fenestrated as could be expected from men unaccustomed to such work.

The first case admitted was a young child about 5 years of age. She had a wide urethra for such a young child, and no dilatation was necessary. The operation was completed without a drop of blood having been lost, the water in the bulb of the aspirator not having been even tinged by it; there were no signs of irritability of the bladder after the operation, and its functions remained unimpaired. No more convincing proof of the good results attending the operation in this hospital can be given than the fact that the children refuse to keep their bed the morning after the operation.

These facts have been brought forward not so much for their intrinsic importance, although that is a sufficient reason, as to render the one which is to follow much more conspicuous; namely, the fact that during the operation no auxiliary fluid could be retained in the bladder. This last mentioned fact was my bugbear, and if I had not been driven to try lithotrity on 
females as the only operation which seemed fitted to preserve in their integrity the functions of the bladder, I should have been afraid to try the operation, about to be described, on males.

It may be said, however, that you can do anything you like with children and they get over it; but the next case operated upon was an old woman, at the other extreme of life. She had a very large stone, suffered from great irritability of the bladder, frequent and painful micturition, and her urine contained pus and was very fotid. Now, although no auxiliary fluid could be kept in the bladder during the operation, very little blood appeared at the meatus urinarius externus during the crushing of the stone, the bulb of the aspirator was only slightly tinged with blood during aspiration, and all symptoms of irritability of the bladder ceased with the evacuation of the debris. The function of the bladder remained intact. The operation was in every way successful.

But to show the success of the operation in all phases of life, as well as in healthy and diseased conditions of the bladder, I may be permitted to introduce also the case of a young girl about the age of 15 , whose bladder was as irritable as in the preceding case. The fœtor of the urine was overpowering during the operation, although disinfectants were freely employed; so penetrating was the odour that I felt it long after the operation was finished. Thestone was, also, a very large one. Now, although no auxiliary fluid could be retained in the bladder, the show of blood during the act of crushing the stone was very insignificant; during aspiration the fluid in bulb of the aspirator was only slightly tinged with blood, for the debris could be seen falling down through it. All symptoms of irritability may be said to have ceased with the final washing out of all the debris from the bladder. Its funetions remained intact after the operation.

I could go on multiplying these experiences. It is only a week or so since I operated on a young child about 6 years of age, using a No. 5 lithotrite with a No. 6 catheter. The debris was evacuated without so much as the appearance of blood in the bulb of the aspirator, and the functions of the bladder were left completely unimpaired, and the child was playing next morning in the verandah as if nothing had happened to her. But now enough, I think, has been put on record to justify the establishment of the following proposition-that lithotrity in the female can be successfully performed in the absence of auxiliary fluid in, and even in the presence of a high degree of irritability of, the bladder, without disturbing its functions in any way

The truth of this proposition being established, it next occurred to me that an operation similar to this could be performed on males whose urethræ were too small to readily admit the lithotrite whose screw coincided with the diameter of the calculus. The narrowest part of the male urethra is the membranous portion. It is only necessary, therefore, to slit open this part of the canal, and the remainder, the prostatic portion, offers no obstacle to the passage of larger instruments. The only step necessary, therefore, to make the operation in the male almost similar to that in the female was to make a direct opening through the perineum into the membranous portion of the urethra large enough to admit a lithotrite whose screw was long enough to embrace the diameter of the stone to be crushed.

I had contemplated the possibility of the perineal method long before the experiences recorded above were realised, but the idea of the impossibility of retaining a sufficient amount of auxiliary fluid in the bladder rose up and condemned the operation in my mind; but the determination to risk any rather than the cutting method in the female, the unexpected success and brilliancy of results which attended my efforts at lithotrity in them, its beauty, simplicity, and perfection urged me on to try a similar operation in males in whom urethral lithotrity was inadmissible on account of the size of the stone and the narrowness of the urethra.

The operation suggested above is performed by me as follows: Introduce a grooved staff into the bladder in the ordinary way in operations for stone, then take a sharppointed narrow-bladed knife, and, holding the staff up against the angle of the pubes, with the left hand firmly resting on the patient, insert its point at the angle formed by the root of the penis with the perineum, and push it upwards and slightly backwards into the groove of the staff, making slight forward and backward movements to make sure of being in it and keep it there. A small director is then to be pushed alongside the knife into the groove of the staff, making with it also some decided backward and forward movement to make sure it is in the groove of the staff, then, having removed the knife, the director is pushed home into the bladder and the staff withdrawn. Thus far there is no difficulty. That the director has entered the bladder is known in two ways. As a rule the stone can be felt and urine escapes from the wound.

It should now be ascertained whether that lithotrite will enter the wound whose screw coincides with the diameter of the stone, the size of which can be most accurately determined by previously measuring it by means of a lithotrite, which the urethra can readily admit. If the wound in the skin and the membranous portion of the urethra is not large enough to readily admit this lithotrite, a probe-pointed knife must be introduced into the groove of the director, and the wound slightly enlarged. Having fitted the wound for the lithotrite, its point is to be gently introduced along the groove of the director with the handle downwards. When the jaws of the instrument have been completely introduced into the wound, by simultaneous movements the director is withdrawn and the lithotrite moved upwards to the perpendicular by a sweeping motion to the right, gently push it into the bladder.

If, by some accident, the director falls out of the wound and its walls collapse, the best way out of the difficulty is to introduce the staff again, and the director may be got into its groove and so into the bladder; if not, another incision must be made, which is bad practice, although I never yet saw any untoward circumstance occur attributable to this contingency. The knife is not to be pushed along the groove of the director in the direction of the bladder; if this be done, the prostate will be in danger of being wounder, and the great aim of the operation will be lost, its end and design being to preserve both the structure and the function of the prostate gland intact. There is, as a general rule, no blood lost after the introduction of the lithotrite, and after it has begun to work, for the wound is in all cases exceedingly small; it is in the mesial line, and only capillary vessels are cut. The debris is removed in the ordinary way by the evacuating catheter and aspirator. In this method the aspirator is necessary as the catheter remains more or less in the horizontal position during aspiration.

Urethral and perineal lithotrity dispose, therefore, not only of all stones whose diameters coincide with the screws of the largest lithotrites that can be readily introduced through the urethra into the bladder, but also of all stones, except very hard ones that lithotrites cannot crush, whose diameters coincide with the screws of any lithotrite made, and yet preserve in their integrity the structure and function of the prostate gland.

By the perineal operation I have successfully removed the largest stones, whose diameters coincide with the length of the screws of the largest lithotrites that can enter the urethra, and firm in the impression that lithotrites of much larger dimensions could be introduced into the bladder without injuring the prostatic portion of the canal after division of the membranous portion, and that this operation could be extended to yet much larger stones without in any way endangering its chief object, I ordered a perineal lithotrite from Messrs. Coxeter and Son which is two sizes larger than the largest lithotrite the urethra can admit, together with a catheter corresponding in size. I have successfully commenced operations with this one, but I believe, as the calibre of the prostatic portion of the canal differs in size in different individuals, I shall require a series of perineal lithotrites and evacuating catheters to perfect the parallel between perineal and urethral lithotrity. This problem will have to be solved by future experience.

The chief peculiarities of this new modification of the lithotrite are its length of screw (which, in order not to make the instrument abnormally long, derives its length by encroaching on the shaft), its massiveness of jaws and shaft, and the strength of the female screw. This last $I$ have found to be the weakest part of urethral lithotrites. When I wrote out the description of the kind of lithotrite I wanted to Messrs. Coxeter and Son, I little thought I should receive an instru 
ment so perfectly adapted in every way to the work it would have to perform. After it came into my possession, only a few days passed before I had an opportunity of testing its merits. The patient was an old man, about 60 , with a urethra so narrow that it would scarcely admit a No. 10; and when the stone was seized by it, the screw was quite outside the box, and when the diameter of the stone was measured, it was found to be a little over the length of the screw of the largest urethral lithotrite. The idea of introducing such a large lithotrite by slitting up the meatus and running the risk of stretching the urethra could not in this case or, in my opinion, in any other case of a patient so far advanced in age, be lightly entertained.

In other hospitals the patient would have had to submit to some one of the usual three operations-the lateral, median, or suprapubic. The small perineal incision was made, and scarcely any hæmorrhage occurred. The new lithotrite passed through the prostatic canal with the greatest ease, the anticipations about the capabilities of the calibre of this part of the canal to admit larger lithotrites being fully realised. The large instrument was as sensitive and as easily handled as could be wished. The first break was the loudest I have heard, as, of course, I had never before crushed such a large stone. After crushing the stone into small fragments, the operation was finished by my favourite No. 10. It is my belief that the lighter and more sensitive the instrument used, the more benefit to the patient. The wound was not too large for the No. 20 evacuating catheter, for no fluid escaped during aspiration from between its walls and the catheter, which invariably takes place if the wound is too large. The operation lasted about two hours, the delay being due to the phosphatic and adhesive quality of the debris of the stone and the consequent difficulty of separating it from the vesical walls. The stone weighed about 2 ounces. The patient passed urine freely by the penis after the operation, and continued to do so afterwards, the wound in the perineum being scarcely even wet during micturition. But the best proof of the success of the operation is the fact that the patient left the hospital cured on the third day after, with the functions of the bladder and prostate intact; and the structure and function of the latter remaining unimpaired, it is reasonable to suppose that the sexual powers were not interfered with. have now done seventy-six of these operations, with only two deaths.

The advantages of the operation may be briefly enumerated as follows :

1. Non-interference with the structures and functions of the bladder and prostate. This can be proved to demonstration. After the operation is finished and the debris evacuated with the large perineal evacuating catheter, introduce the nozzle of a syringe (= a No. 16 catheter) through the wound and empty its contents into the badder: then on withdrawal of the syringe no fluid escapes. But if now the smallest evacuating catheter be introduced the bladder will immediately empty itself through the catheter.

2. Smallness of the wound and no important structures cut.

3. No hæmorrhage to speak of.

4. The scientific accuracy with which the operation can be performed.

5. Urine as a general rule passes, almost if not entirely, by the urethra instead of through the wound, and it is always a voluntary act.

6. The bed clothes are kept dry

7. Speedy recovery.

8. No danger of fistulous openings.

9. Absence of shock, unless the patient be old and weak and with a large stone.

10. Non-interference with the sexual powers as inferred.

11. Mortality comparatively favourable-2 deaths in 76 operations, or 2.6 per cent.

\section{III.-HaMrmer AND ChIski Mathod.}

When the stone is too large for the largest-sized lithotrite then recourse is had to the hammer and chisel method. This was the system adopted before $I$ received my perineal lithotrite; now this method is employed only for those stones which are too large for it.

The object of the operation is t. remove the debris of the largest stones through an opening capable of admitting the largest lithotomy forceps with concave jaws, the amount of débris removed at each time being limited to that contained within the concavity of the closed jaws.

The operation may be described as follows: A wound is made in the median line through the perineum into the bladder, large enough to admit the largest-sized lithotomy forceps with concave jaws. Having introduced the forceps and firmly seized the stone and handed the forceps over to the care of an assistant, a small-pointed chisel, introduced parallel to and on the mesial line of the forceps and pushed onwards until it is felt to be well planted against the stone, it is held so that it cannot pass beyond control and is hit firmly with the hammer. If it is a soft stone a few firm little taps will be sufficient to smash it, if it is a hard one more force will have to be used. In soft stones when it is broken up, as will be shown by the handles of the forceps coming together, then the forceps are withdrawn with the mouthful of débris contained between the closed jaws. Projecting splinters of hard stone must be carefully guarded against. If, by the finger in the rectum they are found projecting beyond the lower side of the forceps it must be partially opened and the projecting portion or splinter pushed within the cavity of the jaws of the forceps or made to project on their upper side; then the forceps being firmly closed a sharp crescent-edged chisel is introduced and the projecting splinter or splinters shaved off. By this method I have successfully removed from one patient 17 ounces of débris. It is resorted to only in very exceptional cases ( 4 per mille), as is shown by comparing the number of stones in the museum of this hospital with the screw of my new lithotrite.

These methods which I have described above for the removal of vesical calculi have in my hands proved satisfactory as being the operation attended by the least risk and with a very fair result as to mortality. I have performed in the"present year 270 operations for stone. Since receiving $\mathrm{my}$ set of lithotrity instruments I have done 157 lithotrities, with 3 deaths, 76 perineal lithotrities, with 2 deaths, and 12 operations with the hammer and chisel method, with 4 deaths. The proof of the success of the operations is seen in the fact that a much larger number of patients flock to the hospital now than formerly. In former years the average number of cases was about 180 per annum. This year, up to the beginning of October, there have been 270 cases ; and as the people come at an early date of their complaint to take advantage of the new methods, it is reasonable to suppose that the few exceptional cases ( $=4$ per mille) of stones too large for the grasp of even my perineal lithotrite will become absorbed by them, and, therefore, the hammer and chisel method will also, along with the cutting methods, sooner or later become obsolete.

As these methods will, with regard to the various terms used for the removal of stone by crushing, make "confusion worse confounded," I have taken the liberty of coining the following word for distinguishing the methods herein advocated, namely, "lithotritlapaxy," hence "urethral lithotritlapaxy" and " perineal lithotritlapaxy."

The Birmingham Medicar Benevolent Socrety.-At the seventieth meeting of the Birmingham Medical Benevolent Society it was announced that the invested funds amounted to $\$ 11,39612 \mathrm{~s}$. 9d., which, together with a balance of $£ 26016 \mathrm{~s}$. $4 \mathrm{~d}$. at the bank, make a total of $£ 11,6579 \mathrm{~s}$. Id. During the year fifteen annuitants received help from the Society, the yearly value of the grants ranging from $£ 40$ to $£ 20$. The total sum expended in grants has been $£ 440$. The directors, while regarding the condition of the Society as satisfactory, regret that it contains so small a proportion of those who reside within the area of its operation. In October 570 appeals drawing attention to the advantages of the Society were sent out, but these can only be fairly credited with the addition of ten members, the remaining fourteen being obtained by personal application. We cannot but think that the Society would be better supported if its good work was more generally known. Mr. John Garner was appointed President for the ensuing year; Dr. Wyer, of Leamington, President-Elect; and Dr. Saundby and Dr. Addenbrooke, Vice-Presidents. Sir James Sawyer and Dr. Savage were reelected Hon. Treasurers, Mr. W. F. Haslam was reappointed Hon. Secretary, and Mr. F. Marsh Hon. Auditor. 